\title{
O uso de técnica eletroquímica para a descontaminação de estruturas cerâmicas vítreas porosas
}

\section{(The use of electrochemical technique for porous vitreous ceramic structure decontamination)}

\author{
O.B.G.Assis ${ }^{1}$ E.R. Silva ${ }^{2}$ \\ ${ }^{1}$ Embrapa Instrumentação Agropecuária, Rua XV de Novembro 1452, S. Carlos, SP 13560-970 \\ ${ }^{2}$ PPG Interunidades Ciência e Engenharia de Materiais, USP, S. Carlos, SP \\ odilio@cnpdia.embrapa.br
}

\begin{abstract}
Resumo
Apresentamos neste trabalho os resultados de ensaios preliminares para avaliar o uso de técnica de eletro-osmose para a remoção de contaminantes orgânicos em estruturas porosas cerâmicas, como filtros ou similares. A técnica consiste em forçar a migração de contaminantes retidos na estrutura interna ou na superfície dos poros por meio da aplicação de tensão controlada em célula eletroquímica projetada para este fim. As moléculas absorvidas na superfície cerâmica estarão sujeitas as ações cisalhantes de uma camada aquosa difusa móvel, e uma vez na condição iônica, migram na direção do campo de carga oposta, sendo posteriormente removidas. Nos ensaios de avaliação da técnica, escolhemos o fenol como contaminante padrão e os testes realizados em membranas vítreas microporosas imersas em solução aquosa. Os dados foram obtidos em função do tempo de aplicação da carga por medidas de densidade ótica e concentração de hidrogenação. Os resultados indicam remoções proporcionais a 70\% do contaminante em estado diluído após 120 min de aplicação de carga.
\end{abstract}

Palavras-chave: eletroosmose, purificação de materiais porosos, filtragem, eletroquímica, fenol.

Abstract

In this study the preliminary results of the use of electro-osmosis technique for the removal of organic contaminants in porous ceramic structure is presented. The method consists in provoke the migration of chemicals retained in the structure or adsorbed on the pores surfaces by application of a controlled tension in an electrochemical cell. The adsorbed molecules underwent shear stress due to a diffuse moving layer, which once in ionic state, the specimens are dragged and move towards the opposite charged electrode. Phenol was chose as standard contaminant and the tests carried out in vitreous porous membranes. The testes were performed in function of charge application and concentration assessed by optical densities. The results show a proportional removal of $70 \%$ of the contaminant in diluted condition after 120 min of charge application.

Keywords: electro-osmosis, decontamination of porous materials, filtration, electrochemistry, phenol.

\section{INTRODUÇÃO}

O emprego de técnicas eletrocinéticas e suas variáveis têm apresentado resultados promissores em processos de purificação de contaminações químicas em águas [1], em meios porosos diversos como leitos cerâmicos [2] e solos [3], e já são corrente as aplicações em processos de geotecnologia como na drenagem e estabilização de encostas [4] e na recuperação de terrenos lateríticos de textura fina [5]. Essas técnicas têm como princípio a migração de espécies adsorvidas ou retidas em um meio permeável ou poroso, sob a ação de um campo elétrico externo aplicado por meio de eletrodos que geram no sistema uma camada difusa móvel que carrega com ela os compostos polares presentes em solução. Na presença de um meio poroso, a fração sólida é considerada fixa com relação ao movimento da camada líquida, sendo este fenômeno denominado eletro-osmose [6]. A eletro-osmose pode ser considerada assim como um complemento da eletroforese, onde suas fases, estacionárias e móveis, estão trocadas com relação às estabelecidas para a eletroforese [7]. O processo de migração por eletroosmose se torna mais eficaz quando os compostos transportados estão carregados ionicamente. Nestas condições, pode-se, teoricamente, conceituar o fenômeno de eletroosmose como um transporte por meio de capilares. Ou seja, para um dado valor de tensão aplicada podemos medir a velocidade e a força que um fluído exerce ao movimentar-se por entre o perfil poroso. Neste modelo o meio pode ser considerado como um capilar genérico, obtendo-se desta forma a pressão osmótica ou o volume do líquido transportado por unidade de tempo.

Segundo o modelo clássico de fricção [8], o transporte 
eletro-osmótico da água por unidade de carga elétrica, é elevado com o aumento da relação água/cátion no sistema, a relação entre o volume de água pela quantidade de corrente imposta no sistema fica assim expressa por:

$$
\frac{\mathrm{V}}{\mathrm{I}}=-\frac{\varepsilon \varsigma}{\mu\left(\lambda_{0}+2 \lambda_{\mathrm{s}} / \mathrm{d}\right)}
$$

sendo $\mathrm{V}$ o volume do fluxo por unidade de tempo, I a corrente, $\mathrm{d}$ o diâmetro médio de poros, $\lambda_{0}$ a condutância específica do líquido e $\lambda_{\mathrm{s}}$ a condutância de superfície da parede capilar. Assim, em uma estrutura com distribuição estreita de poros e/ou em sistemas com soluções de baixa concentração iônica, pode-se inferir experimentalmente a relação V/I [9]. Na prática, estabelecemos em função da corrente um fluxo estacionário de arraste das espécies carregadas em direção ao catodo, em concordância com o esquema da Fig. 1. Esse fluxo é cisalhante e possui elevada capacidade de remoção de espécies adsorvidas nas paredes dos poros.

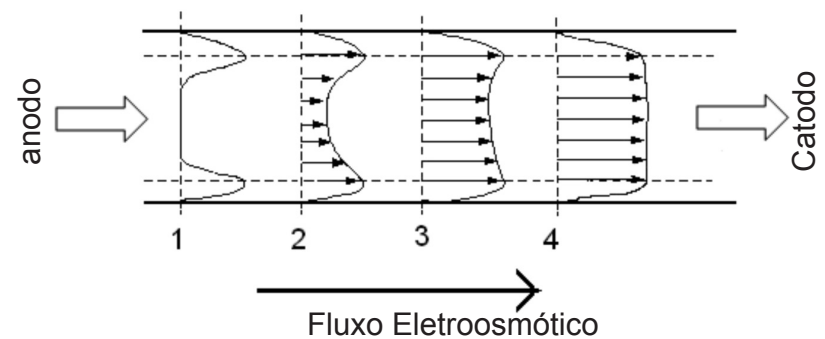

Figura 1: Modelo do desenvolvimento do fluxo eletro-osmótico dentro de um poro: em 1 estabelecimento do campo; em 4 o fluxo já se encontra em estado estacionário.

[Figure 1: Model of electro-osmotic flux development inside a pore: in 1 the initial establishment of the field; in 4 the flux is already in steady state.]

A unidade da Embrapa Instrumentação Agropecuária em S. Carlos, SP, já há algum tempo tem avaliado potenciais usos de membranas porosas e meios particulados vítreos para usos como dispositivos de pequeno porte para microfiltração de água $[10,11]$ para a imobilização de agentes ativos [12] e na liberação de compostos voláteis [13]. Esses dispositivos, de baixo custo e de fácil confecção, prestam para uso geral e em particular na zona rural, visando a retenção de metais pesados e a recuperação de águas contaminadas por agrotóxicos [14]. Contudo, a alta afinidade entre a superfície vítrea e os compostos aromáticos [15] presentes na composição da maioria dos agroquímicos, dificulta uma limpeza eficiente e o reuso desses elementos após a saturação de contaminantes.

A simples lavagem, seja por fluxo forçado de água ou por ação mecânica (escovação), não é eficiente para a remoção dos orgânicos retidos nos poros, fazendo necessários tratamentos químicos ou elétricos para uma limpeza mais efetiva. Assim, o propósito deste trabalho é idealizar um experimento para a avaliação do potencial do emprego do principio de eletro-osmose na remoção de compostos orgânicos retidos internamente em peças porosas. O contaminante teste aqui avaliado foi o fenol sendo a metodologia abrangente e em particular útil para a purificação e manutenção de filtros cerâmicos.

\section{MATERIAIS E MÉTODOS}

Preparou-se inicialmente uma solução estoque com fenol a $6 \mathrm{mg} / \mathrm{mL}$ por dissolução em água destilada (fenol comercial, Synth). Diluições a partir dessa concentração foram realizadas, levantando uma curva de calibração entre concentração e medida de densidade ótica obtida em espectroscopia de UV-Vis (Shimadzu, UV-1601PC). As medidas foram de absorbância e consideradas no comprimento de onda $270 \mathrm{~nm}$ [2], estabelecendo uma relação linear semi-quantitativa. A montagem experimental consistiu na confecção de uma cuba em acrílico para volume útil de $1125 \mathrm{~cm}^{3}$, com câmaras laterais isoladas por membranas de nylon microporoso para os eletrodos. A cuba foi conectada a sistema de circulação de água para remoção das espécies migradas e controle de nível. O objetivo foi limitar o meio em um volume definido. Empregamos como meio poroso membranas vítreas planas confeccionadas por sinterização com porosidade volumétrica entre 29 a $32 \%$ e tamanho médio de poros em torno de $30 \mu \mathrm{m}[10,11]$. As peças foram previamente embebidas em solução de fenol na concentração de $1 \mathrm{mg} / \mathrm{mL}$ em dissecador sob ação de vácuo leve para preenchimento dos poros e seqüencialmente imersas na cuba preenchida com água deionizada. A Fig. 2 esquematiza a montagem experimental. $\mathrm{O}$ volume ocupado pelo meio poroso não foi superior a $60 \%$ do total. $\mathrm{O}$ pH inicial da água anterior a imersão das membranas foi medido como 5,56. Empregamos eletrodos de titânio com área de trabalho igual a $26 \mathrm{~cm}^{2}$. Os testes foram realizados sob tensão de $60 \mathrm{~V}(\mathrm{dc})$ e corrente constante de $5,0 \mathrm{~mA}$ aplicadas diretamente nos eletrodos [16, 17]. O processo foi monitorado pela medida do $\mathrm{pH}$ em amostras recolhidas nas regiões do anodo e do catodo e a eficiência de remoção avaliada por espectroscopia de UV-Vis a cada 20 min até um total de $2 \mathrm{~h}$ de ação da tensão.

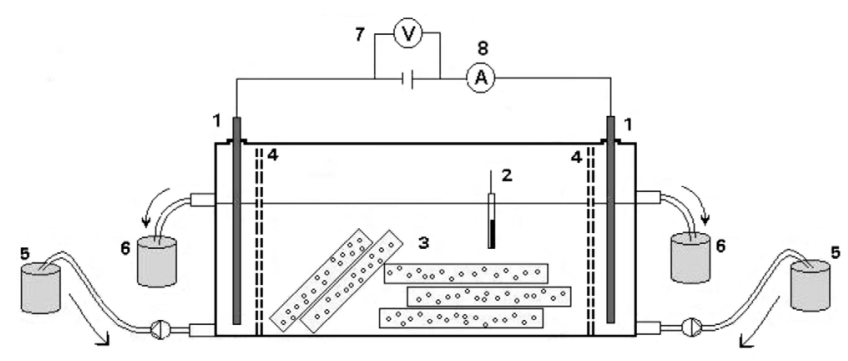

Figura 2: Montagem experimental: 1 - Eletrodos, 2 - pHmetro, 3 - Peças cerâmicas, 4 - Membrana de nylon, 5 - Recipiente para preenchimento, 6 - Recipiente de recolhimento (manutenção do nível e coleta para análise), 7 - Fonte dc, 8 - Amperímetro.

[Figure 2: Experimental set up: 1 - electrodes, 2 - pH meter, 3 - ceramic pieces, 4- nylon membrane, 5 - container for influx, 6 - collection container (level maintenance and sample analysis),

7 - dc power supply, 8 - Current meter.] 


\section{RESULTADOS E DISCUSSÃO}

Na presença das membranas, após um breve período de estabilização sem aplicação de carga ( 15 min), o pH medido na água elevou-se para 7,35 mantendo-se nessa média ao longo de medidas tomadas a cada $20 \mathrm{~min}$ (Fig. 3a). Esse valor indica a dissolução espontânea do fenol associado ao um potencial alcalino apresentado por vidros a base de silicatos de sódio na presença em meio liquido [18]. Com a aplicação da carga é estabelecido o movimento simultâneo de produtos gerados pela eletrólise da água $\left(\mathrm{OH}^{-}\right.$e $\left.\mathrm{H}^{+}\right)$em conjunto ao fluxo de moléculas decorrentes da inserção do fenol $\left(\mathrm{C}_{6} \mathrm{H}_{5} \mathrm{OH}\right)$. O fenol dissocia-se em $\mathrm{C}_{6} \mathrm{H}_{5} \mathrm{O}^{-}+\mathrm{H}^{+}$com interações similares às da hidrólise da água. Sendo as reações de superfície marcadas pela eletromigração de grupos hidroxilas $\mathrm{OH}^{-}$para a região do anodo e íons $\mathrm{H}^{+}$para a região do catodo. Com o estabelecimento do arraste do fenol a montagem permite a troca da água nas proximidades dos eletrodos extraindo assim o contaminante migrado. A Fig. 3 apresenta a variação de $\mathrm{pH}$ nas regiões dos eletrodos em tempos variáveis indicando a evolução do processo em função do tempo. As reações de eletrólise acontecem no anodo concentrando na região uma alta hidrogenização, acusada pela queda do $\mathrm{pH}$ na região, confirmando a migração das espécies.

Comparando os espectros de UV-Visível correspondentes ao inicio e após o período de 120 min na região do anodo (Fig. 4), tem-se um indicativo da redução do teor de contaminante em solução. Com base na curva de calibração previamente estabelecida, a redução na absorbância indica que após esse período de aplicação de carga a concentração de contaminante em solução encontra-se a 33\% com relação a medida inicial. Como este é um processo contínuo, porções constantes de contaminantes são migradas e removidas até um limite em que a fração iônica em solução não é passível de detecção. Colocando seqüencialmente estes valores em função do tempo (Fig. 5), observa-se um decaimento com perfil ligeiramente exponencial com relação à remoção de fenol do meio líquido. Os resultados claramente indicam a eficiência do processo.

A título de fundamentação experimental, devem ser consideradas nestes resultados, ou em procedimentos similares de remediação química, as interações que tomam lugar entre a superfície oxidas (vidros, cerâmicas e cristais argílicos de um modo geral) e as moléculas fenólicas (fenol, herbicidas, etc.). Os óxidos apresentam conhecida organofilicidade e alta capacidade de adsorção de espécies hidrofílicas [19], sendo assim altamente reativo com o fenol. Nestas condições uma fração significativa do contaminante se liga quimicamente com a superfície óxida. Há forte possibilidade de ocorrência de interação com a superfície em função da presença de cargas; entretanto, interações de grupos hidrofóbicos, assim como as ligações de hidrogênio e formação de complexos, evidentemente devem ser consideradas. No caso específico do vidro, a superfície é composta de ligações siloxanas ( $\mathrm{Si}-\mathrm{O}-\mathrm{Si}$ ) e, sobretudo por grupos silanóis ( $\mathrm{SiOH})$. Os grupos silanóis se distribuem aleatoriamente na superfície e são altamente polares, embora na presença de água possa se dissociar gerando estruturas com cargas superficiais [20].

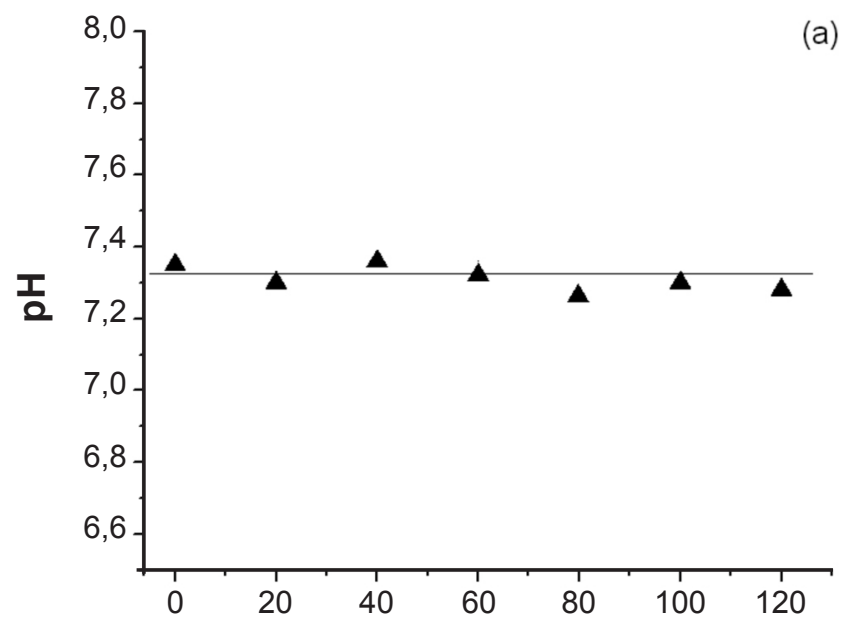

(b)

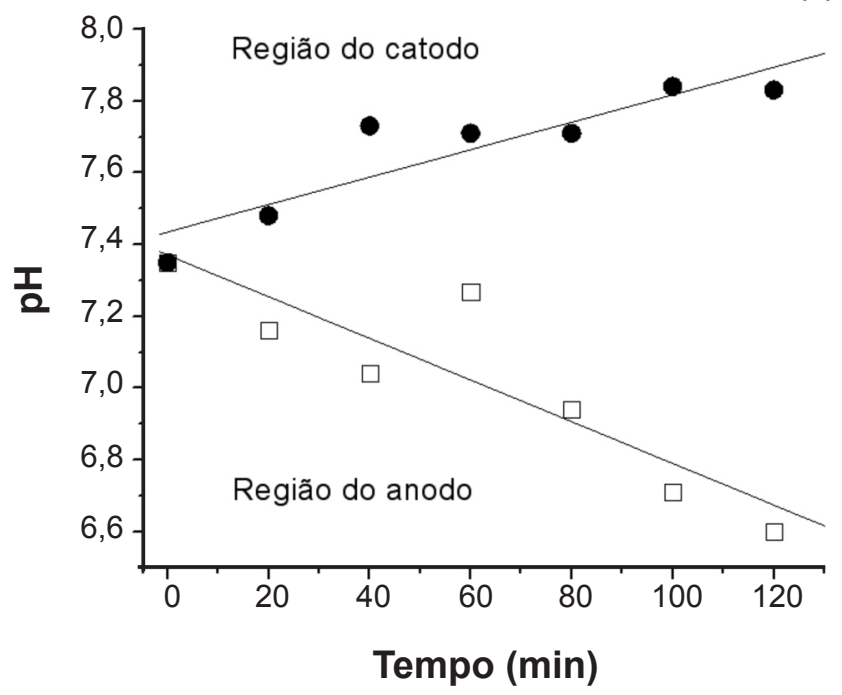

Figura 3: pH medidos nas regiões de reações: (a) sem aplicação de carga e (b) com aplicação de carga $(60 \mathrm{~V}$, dc) e medidas realizadas nas proximidades dos eletrodos na célula.

[Figure 3: pH measured in reaction regions: (a) with no applied charge and $(b)$ with charge on $(60 \mathrm{~V}, d c)$ and measurements carried out in electrodes surrounding.]

Assim, pode-se, com base em conceitos simples, sugerir duas possíveis ocorrências de interação como as representadas na Fig. 6. Na reação 1 temos uma interação da superfície com moléculas de fenol por ligações de hidrogênio. Este tipo de ligação é consideravelmente fraca e instável, embora haja aqui a possibilidade de ocorrência. Na reação 2 temos o estabelecimento de uma ligação mais estável, que ocorre com a protonação do fenol favorecendo ligações do anel benzênico com a superfície do óxido. É uma ligação passível de ocorrência, embora menos provável. Essas reações são especulativas e não confirmadas.

Os resultados obtidos, principalmente os dispostos na Fig. 5, indicam claramente que essas ligações, ou outras passíveis de ocorrência, são rompidas ao longo do processo de aplicação de carga e geração de fluxo cisalhante, fazendo com que as espécies sejam migradas em direção 


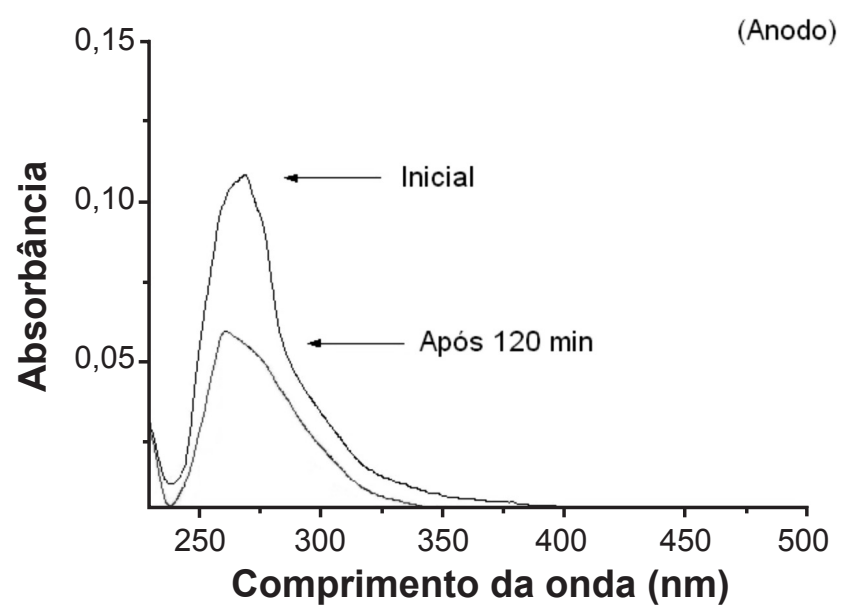

Figura 4. Espectros UV-Vis correspondentes a absorbância de fenol em amostras de soluções após a estabilização por 15 min (inicial) e ao final de 120 min de carga na região do anodo.

[Figure 4: UV-Vis spectra correspondent to phenol measured in the anode surroundings in samples after stabilization of $15 \mathrm{~min}$ (Initial) and after 120 min under charge application.]

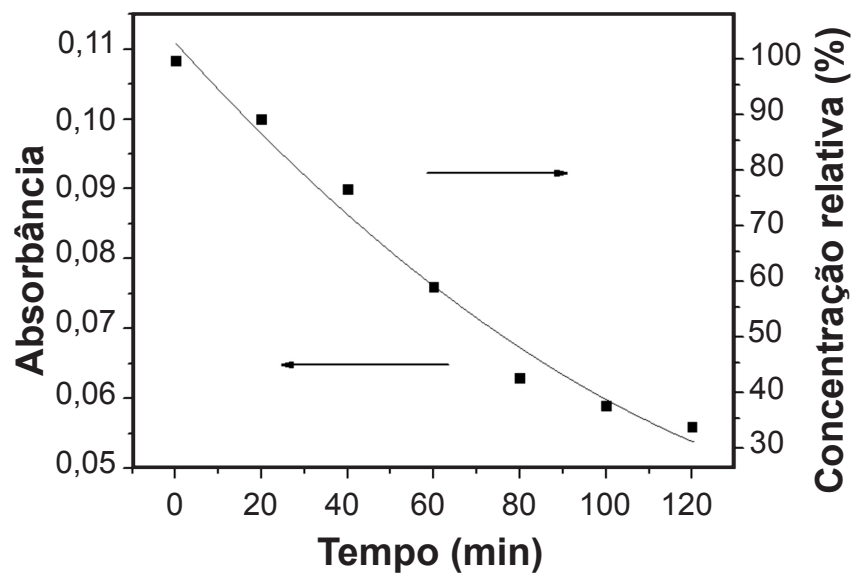

Figura 5: Variação da absorbância (a $270 \mathrm{~nm}$ ) e correspondente concentração de fenol em função do tempo de aplicação de carga (60 V (dc) e I = 5,0 mA).

[Figure 5: Absorbance variation (at $270 \mathrm{~nm}$ ) and correspondent phenol concentration in function of time of charge application (60 $V(d c)$ and $I=5.0 \mathrm{~mA})$.]

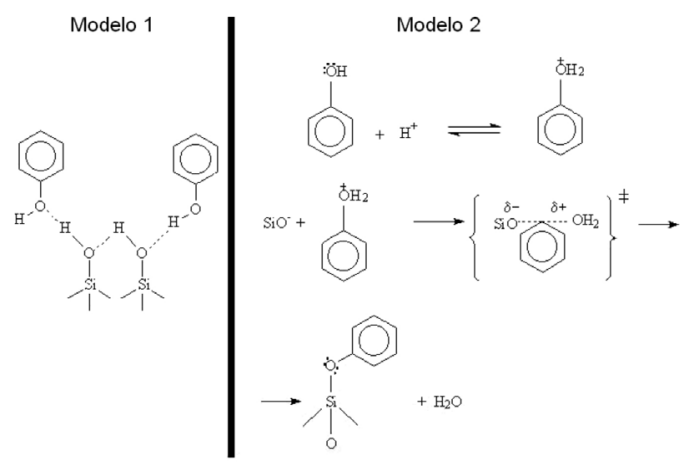

Figura 6: Modelos tentativos de adsorção e interação do fenol com superfícies de óxido de silício.

[Figure 6: Tentative models for adsorption and phenol interaction with silicon oxide surfaces.] aos eletrodos, confirmando a eficiência do processo na escala aqui empregada.

\section{CONCLUSÕES}

Este trabalho, ainda que preliminar, confirma o potencial de emprego de técnicas eletroquímicas como metodologia coadjuvante na purificação de contaminantes orgânicos em estruturas cerâmicas porosas. Nas condições experimentais, remoção de fenol na ordem de $70 \%$ foi confirmada. Melhoramento experimental e uma avaliação mais criteriosa dos parâmetros envolvidos no processo, como distância entre os eletrodos, carga, corrente, fração sólida, caráter do eletrólito, etc., que devem ser considerados em cada caso visando uma melhor eficiência do processo.

\section{REFERÊNCIAS}

[1] E. R. Silva, O. B. G. Assis, Eng. Sanitária e Ambiental 9, 3 (2004) 1-4.

[2] E. R. Silva, O. B. G. Assis, Anais Assoc. Bras. Quím. 51, 2 (2002) 53-57.

[3] V. Merminod, C. Comninellis, Proc. Energy and Electrochemical Processing for a Cleaner Environment, The Electrochem. Soc., Pennington, NJ, EUA (1998) 315-322.

[4] F. Burnotte, G. Lefebvre, G. Grondi, Can. Geotech. J. 41, 6 (2004)1038-1053.

[5] Y. B. Acar, R. J. Gale, G. Putnam, J. Hamed, Proc. $2^{\text {nd }}$ Int. Symp. Environmental Geotechnology 1, Shangai, China (1989) 25-38

[6] H. D. Crockford, Fundamentos de físico-química. $1^{\mathrm{a}}$ Ed., LTC, Rio de Janeiro, RJ (1977) 383p.

[7] C. M. A. Brett, A. M. O. Brett, Electrochemistry: Principles, Methods, and Applications. $1^{\text {st }}$ Ed., Oxford University Press, New York, EUA (1993) 427p.

[8] K. S. Spiegler, Trans. Faraday Soc. 54, 9 (1958) 14081428.

[9] A. T. Yeung, S. Datla, Int. J. Rock Mech. Min. Sci. Geomech. Abstr. 33, 2 (1996) 60A-61A.

[10] O. B. G. Assis, M. Ferrante, D. C. Viera, Glass Techn. 42, 3 (2001) 101-103.

[11] O. B. G. Assis, Cerâmica 52, 321 (2006) 105-113.

[12] O. B. G. Assis, D. Britto, J. Polym. Environ. 16, 3 (2008) 192-197.

[13] R. M. Takahashi, O. B. G. Assis, Cerâmica 54, 332 (2008) 462-465.

[14] O. B. G. Assis, D. C. Vieira, Rev. Bras. Eng. Agríc. Ambiental 13, 3 (2009) 341-345.

[15] S. C. Ringwald, J. E. Pemberton, Environ. Sci. Techn. 34, 2 (2000) 259-265.

[16] V. Merminod, “Application de L'Électroosmose et de L'Électromigration a L'Extraction de Polluants Organiques et Inorganiques de Sols Pollues", These (Docteur), Ecole Polytechnique Federale de Lausanne, Suiça (1998) 239p.

[17] E. R. Silva, "Uso de Técnicas de Eletroosmose para Purificação de Sistemas Particulados", Diss. Mestrado, Programa Interunidades em Ciência e Engenharia de 
Materiais, USP, S. Carlos, SP (2001) 89p.

[18] Y. P. Cheremisina, V. A. Sirenek, A. S. Aloi, V. A. Kholodnov, Glass Phys. Chem. 35, 4 (2009) 355-359.
[19] P. Chartier, Verre 3, 3 (1997) 5-13.

[20] C. W. Sinton, W. C. Lacourse, Mater. Res. Bull. 36, 13 (2001) 2471-2479.

(Rec. 23/02/2010, Ac. 27/03/2010) 